Western University

Scholarship@Western

Aboriginal Policy Research Consortium International (APRCi)

2006

\title{
Indigenous Healing Practices among Rural Elderly African Americans
}

Debra A. Harley

Follow this and additional works at: https://ir.lib.uwo.ca/aprci

Part of the Community-Based Research Commons, $\underline{\text { Health Policy Commons, and the Medicine }}$ and Health Commons

Citation of this paper:

Harley, Debra A., "Indigenous Healing Practices among Rural Elderly African Americans" (2006). Aboriginal Policy Research Consortium International (APRCi). 186.

https://ir.lib.uwo.ca/aprci/186 
This article was downloaded by: [University of Western Ontario]

On: 18 November 2012, At: 08:11

Publisher: Routledge

Informa Ltd Registered in England and Wales Registered Number: 1072954 Registered

office: Mortimer House, 37-41 Mortimer Street, London W1T 3J H, UK

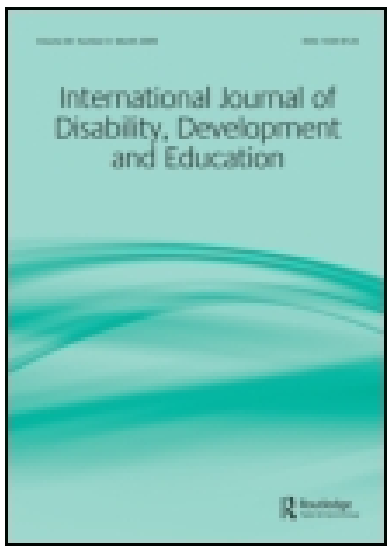

\title{
International J ournal of Disability, Development and Education
}

Publication details, including instructions for authors and subscription information:

http:// www.tandfonline.com/loi/ cijd20

\section{Indigenous Healing Practices among Rural Elderly African Americans}

\author{
Debra A. Harley ${ }^{a}$ \\ a University of Kentucky, USA \\ Version of record first published: 28 Nov 2006.
}

To cite this article: Debra A. Harley (2006): Indigenous Healing Practices among Rural Elderly African Americans, International J ournal of Disability, Development and Education, 53:4, 433-452

To link to this article: http:// dx. doi.org/ 10.1080/ 10349120601008605

\section{PLEASE SCROLL DOWN FOR ARTICLE}

Full terms and conditions of use: http://www.tandfonline.com/page/terms-andconditions

This article may be used for research, teaching, and private study purposes. Any substantial or systematic reproduction, redistribution, reselling, loan, sub-licensing, systematic supply, or distribution in any form to anyone is expressly forbidden.

The publisher does not give any warranty express or implied or make any representation that the contents will be complete or accurate or up to date. The accuracy of any instructions, formulae, and drug doses should be independently verified with primary sources. The publisher shall not be liable for any loss, actions, claims, proceedings, demand, or costs or damages whatsoever or howsoever caused arising directly or indirectly in connection with or arising out of the use of this material. 


\title{
Indigenous Healing Practices among Rural Elderly African Americans
}

\author{
Debra A. Harley* \\ University of Kentucky, USA
}

\begin{abstract}
Elderly African Americans residing in rural areas have practiced and continue to practice indigenous healing practices for various reasons. In addition to the belief in the value of such practices, many of these individuals practice indigenous healing because it is cost effective. In this article information is presented on the history of research on indigenous healing practices, theories and models of indigenous healing in the United States, cultural influence, and views of health care providers regarding such practices. This article concludes with a discussion of the relevance of indigenous healing practices across disciplines and approaches, and recommendations of using participatory research as a means to understand indigenous healing practices among elderly African Americans.
\end{abstract}

Keywords: African American; Elderly; Healing; Indigenous; Rural

\section{Introduction}

The twenty-first century has begun with a continuous global health crisis (e.g., AIDS, bird flu, drug abuse, malnutrition, and starvation) that threatens to incapacitate entire communities and countries. To respond to this crisis will require the biomedical community to access and harness as many resources and partners as possible. Often overlooked and underestimated is the role of indigenous healing or traditional medicine and healers, and the potential contribution they can make at various levels of health care delivery (Pro-Cultura Inc., 2004). Indigenous healing or traditional medicine refers to the practices and knowledge that existed before the advent of modern conventional medicine that were used to promote, maintain, and restore health and well-being. Indigenous knowledge represents the accumulated experience, wisdom, and know-how unique to a given culture, society, and/or

\footnotetext{
*Department of Special Education and Rehabilitation Counseling, The University of Kentucky, 229 Taylor Education Building, Lexington, KY 40506-0001, USA. Email: DHARL00@uky.edu
} 
community. It stands apart as a distinctive body of knowledge that has evolved over many generations in a particular ecosystem (Obomsawin, 2002).

The application of indigenous healing includes designated helpers or healers within a culture who provide various forms of assistance, healing, and/or guidance to individuals who seek intervention for particular problems (Harley, 2005a). In the United States, indigenous healing practices are also referred to as traditional medicine (Center for Traditional Medicine, 2003), complementary and alternative medicine (CAM) (Alcock, 1999; National Center for Complementary and Alternative Medicine [NCCAM], 2004a), and folk medicine (e.g., home remedies, herbal medicine, supernatural forces) (Pickney, 1998). These indigenous practices include everything ranging from herbal medicine and therapeutic touch to prayer at a distance and faith healing (Council for Scientific Medicine, 2002).

The purpose of this article is to describe indigenous healing practices and cultural beliefs among rural elderly African Americans in the United States. Information is presented on this population with regard to (a) an overview of the evolution of indigenous healing practices and CAM, (b) the history of research on indigenous practices, (c) theories/models of indigenous healing in the U.S., (d) current research on indigenous healing practices, (e) current techniques of indigenous healing, (f) cultural influences on the availability and use of indigenous healing, (g) views of indigenous healing as a health service, and $(\mathrm{h})$ the relevance of indigenous healing practices across disciplines and approaches. The reader is encouraged to review and analyse this information within the context of intracultural variation, generational maturation, heterogeneity, and different rates of acculturation and assimilation among African Americans in the United States.

\section{Overview}

In the United States, much of what is considered indigenous healing practices is associated with (but not limited to) American Indians, Mexican, and Native Hawaiin cultures (Indigenous Women's Network, 2004). Similar to previously mentioned groups, African Americans meet the definition of indigenous peoples in several ways. First, African Americans have witnessed, been excluded from, and have survived modernity and imperialism. Second, they have experienced discrimination, isolation, and exclusion from participation as full citizens and colonialism of the modern historical period beginning with the Enlightenment. Third, they remain culturally distinct, with many of their native belief systems still alive. Fourth, they survive outside their traditional lands because they were forcibly removed from them and their connections. Finally, African Americans carry the label of a racial/ethnic minority (Smith, 2005).

Indigenous populations in the United States are assisted with the development of social justice issues and the oversight of medical research by two distinct organisations. On the social justice side, the Indigenous Law Institute assists American Indian and other indigenous communities to develop a radically new basis for thinking about Native rights. The Indigenous Law Institute uses a Traditional Native 
Law perspective and contends that Native nations and peoples have an inherent right to live free of all forms of empire and domination (Indigenous Law Institute, 2006). On the medical research side, the federal agency designated to explore CAM research is the NCCAM. The NCCAM is one of 27 institutes and centres that make up the National Institutes of Health. The National Institutes of Health is one of eight agencies under the Public Health Service in the Department of Health and Human Services. NCCAM supports CAM in the context of research (e.g., grants, laboratory-based studies), research training and career development (e.g., grants, pre-doctoral and post-doctoral and career researchers), outreach (e.g., conferences, educational programmes, an information clearinghouse, website, publications), and integration (e.g., model programmes, public health curricula). In fact, the growing use of unsubstantiated CAM therapies by people in the United States along with insurance companies' willingness to pay for these therapies encouraged Congress to create the NCCAM (Nahin \& Straus, 2001). The importance of CAM has evolved over time and is recognised as a viable avenue of health research. Although the NCCAM was established in 1991, it was not until 2001 that the agency specifically addressed racial and ethnic health disparities. See the Appendix for a chronicle of important events in NCCAM history.

Although there are no laws specifically governing indigenous healing practice for African Americans, healing practices are recognised as commonly occurring in African American culture (Harley, 2005a, b; Harley, Savage, \& Kaplan, 2005; Helms \& Cook, 1999; Lee \& Armstrong, 1995; Nicholls, 1995; Parham \& Parham, 1997; Pinckney, 1998). The origins of African-American folk belief can be traced back to 1619 when slaves were brought to the United States. Slaves preferred selftreatment or treatment by friends, older relatives, or conjure doctors. Religion was and is interwoven into health care beliefs and practices from that time (Eaves, 2005). For African Americans, indigenous healing practices (i.e., a way of doing) are methods, techniques, and materials that they use as a result of their heritage and relocation to the New World to heal, cure, and respond to physical/medical conditions and psychological circumstances. Similar to American Indians, African Americans carry the scars of generations of trauma due to Eurocentic domination and colonial abuse of their languages, cultures, and traditions (Smith, 1999). In African-American cultures, ordained ministers or clerics are viewed as indigenous helpers, especially in matters of mental health or psychological distress (Harley, 2005b; Rivera, Garrett, \& Crutchfield, 2004). For African Americans the process of indigenous healing takes different forms including spiritual practices (e.g., prayer, hope and healing), folk magic (e.g., rituals, incantations, voodoo, hoodoo, use of roots, spells), counselling (e.g., advice, information), and medications (e.g., potions, herbs), and typically involves listening to the problems of a "sufferer" to develop therapeutic interventions (Church Health Center of Memphis, Inc., 2002; Helms \& Cook, 1999; Pinckney, 1998; Rosmaiti, 1999).

The reason for the use of the traditional, culturally based practices of a population is to remove imbalance in their lives and to yield efficacious outcomes (Harley, 2005a). For elderly African Americans in rural areas, indigenous healing practices 
typically are based on nuances of the African culture (Morris, 2000), are holistic, and are based on knowledge of self rather than context (Highlen, 1996; Mpofu \& Harley, 2002). African-American healers draw their authority from a collective understanding of health and healing that was integral to their culture under slavery (Fett, 2002).

Of the current U.S. population, $93.5 \%$ of elderly African Americans are primarily concentrated in seven southern states (i.e., Mississippi, Louisiana, Alabama, Georgia, Virginia, North Carolina, and South Carolina) (Coward, Netzer, \& Peek, 1998). This geography is important in understanding indigenous healing practices and their link to African cultures, especially due to the relocation of Blacks as slaves to these areas. Georgia and the South Carolina Sea Islands offer more concentrated evidence of African cultural retentions (Fett, 2002). African-American healing traditions, which are still thriving today, while deeply embedded in the regional history of the American South, must also be understood in this context of the African Diaspora (Fett). Traditionally, African Americans have found alternative methods for dealing with physical/medical illnesses and psychological distress (Lee \& Armstrong, 1995). In fact, for African Americans, indigenous healing practices have been a hallmark of wellness (Harley, 2005a) and part of the strategies used to respond to life challenges (Harley et al., 2005; Nicholls, 1995). In many ways, African-American indigenous healing is as much about human interactions as diseases or treatments (Fett).

\section{History of Research on Indigenous Practices}

Indigenous healing practices among elderly African Americans, regardless of geographical location, have their origins in African folk medicine and practices. Unknowingly, slave traders brought together an array of healing systems when they hurled together Africans from Igbo, Yoruba, Bambara, Kongo, and other regions. These Africans transformed their distinct traditions of healing to survive in the New World. African-American communities in slavery nurtured a rich health culture, a constellation of ideas and practices related to well-being, illness, healing, and death, that worked to counter the onslaught of daily medical abuse and racist scientific theories. At each historical juncture, enslaved communities cultivated their own practitioners and therapies, and they influenced Southern rural health practices in the process. In fact, enslaved practitioners, while barred from both male professional and white maternal authority, created an original definition of healing authority, which formed a critical part of Southern domestic healing (Fett, 2002). Although it took western medicine 1,000 years to realise the connection between a troubled mind and bodily sickness, African Americans knew it from the beginning. The power of indigenous healing works simply because people believe it works (Pinckney, 1998).

Biomedical approaches have their own merits but are not well equipped to analyse the experiential or political dimensions of health, especially those of indigenous healing knowledge embedded in alternative epistemologies (Fett, 2002). Major reasons for this lack of ability are the historical ideals of racial, gendered, and class-based 
constructions and hegemony (i.e., consensual social practices) as continual resistance to who is "fit" to claim the privileges of medical authority (Lee \& Armstrong, 1995; Helms \& Cook, 1999; Fett 2002). Consequently, the sociohistorical record becomes an unrelenting monocultural narrative of biomedical approaches, while the denial of any indigenous influence and ideology on health care also "invisibilises" (King, 2001) the connection between traditional medicine and well-being.

Nahin and Straus (2001) identified several problems with the research designs for CAM or practices. First, despite emphasis on multimodality treatment regimens among CAM practitioners, most research investigating traditional systems of medicine have examined only one, or perhaps two, interventions taken from a whole treatment system. Second, research design is further confounded by the wide variation in how many forms of CAM are practiced. Third, difficulties in accruing, randomising, and retaining patients are other potential areas of concern. Fourth, finding appropriate placebos or shams for treatments such as herbal mixtures is challenging. In addition, research efforts are hampered by secrecy about folk practices used by indigenous healers. The particular focus on rural elderly African Americans reveals limited research on this population and their indigenous healing practices. Much of the existing research describes this population in relation to aging, health status, the religion-health connection, and income.

\section{Theories/Models of Indigenous Healing}

Non-western indigenous healing methods consist of some basic principles that seem to form the foundation of the credibility and effectiveness of the healers who practice them (Lee, 1996). These principles can be summarised within the context of the Universal Shamanic Tradition (Lee \& Armstrong, 1995). While cultural distinctions exist in the Universal Shamanic Tradition, three salient characteristics define traditions of indigenous healing methods: religion and spiritualism, various levels of human experience, and a holistic approach to healing (Lee \& Armstrong). The healing practices found within the Universal Shamanic Tradition can generally be conceptualised within a philosophical framework that goes beyond objectivity and deductive reasoning, and is characterised by intuitive reasoning and qualitative understanding (Lee).

The major theories/models of indigenous healing practices among African Americans include the energy model (Trieschmann, 1995), NTU (pronounced intoo) psychotherapy (Myers, 1988), humoral theory (Diversity Resources, 2000), and a theory of resistance (Parry, 1994). The energy model integrates the body, mind, emotions, and soul into a philosophy of health and wellness that links African Americans to nature, the core of African cosmology and healing for centuries. NTU psychotherapy is a form of therapy based on Africentric principles of healing that emphasises harmonious connectedness with one's spirituality as a guiding force for optimal functioning (Myers). The core principles of NTU are (a) harmony, being flexibly in charge of one's life without controlling or fighting the unpredictable circumstances of one's life; (b) balance, aspects of life, nature, or oneself that appear 
to be dichotomous (e.g., masculinity-femininity), that are present in all of nature, and that must be integrated into a unified whole; and (c) interconnectedness, a cosmic or spiritual universal force that connects all of life (Phillips, 1990). The intended and ultimate outcome of NTU therapy is that "[the] client should be more keenly aware of self and others, engage life in a more authentic manner, and incorporate effective tools for clear identification, analysis, and resolution of future life difficulties" (Phillips, 1990, p. 72).

Humoral theory, based on Aristotelian and early European medical beliefs, is a part of the African-American folk medical system. The theory of humors focuses on the regulation of the body by the four humors, or major bodily fluids: blood, phlegm, black bile, and yellow liver (Diversity Resources, 2000). A theory of resistance involves a "reverse-discourse" based on "counter-identification and disidentification" (Parry, 1994, pp. 172, 176). In essence, this theory critiques whiteness as a visible maker of what has come to be accepted as superior, and acknowledges the interrelationships of colonialism, racism, and oppression. It applies race, class, and gender analysis to all areas of existence as a way of decolonising the mind (Parry). A theory of resistance is one in which the native intellectual has to identify certain parameters and find a way out of the dichotomies that position the individual as one of the oppressed and marginalised (Weenie, 2000). Hooks (1992) added that one strategy of resistance involves interrogating western thought and being unwilling to confirm what the powerful have to say. The application of each of these theories or models varies according to African Americans' link to indigenous beliefs, geographical locations, and rates of assimilation.

African Americans also believe in the use of polarity therapy (although not unique to them) in the healing process. Polarity therapy was developed in the United States in the late 1940s by Dr Randolph Stone (1890-1981), an osteopath, naturopath, and chiropractor who had a deep interest in eastern medicine. Polarity therapy is a method of healing based on the concept that life-giving energy permeates every part of the human body, and addresses the physical, emotional, and spiritual well-being of an individual, suggesting that energy blockages in one area are reflected in all (WholeHealthMD, 2000). To treat these blockages, the therapy uses four different approaches: bodywork (touch), nutritional counselling (detoxifying diet), stretching postures (yoga-type postures combined with vocal expression), and psychological counselling (listening and support). Each of these approaches is similar to the folk beliefs about health and illness of African Americans. For example, African Americans see the four major causes of natural illness as cold, dirt, improper diet, and improper conduct. African Americans believe that natural illnesses occur when a person fails to monitor or manipulate the bodily processes correctly, thus rendering the body unprepared to defend itself against the forces of nature (Diversity Resources, 2000).

\section{Current Research}

Almost two-thirds of the earth's 6.1 billion people rely on the healing power of CAM because, for them, nothing else is affordable. Even in the United States, use of 
non-prescription botanical drugs and supplements is rising dramatically (Folk Beliefs and Folk Medicine, no date). However, current research on indigenous healing practices among African Americans, particularly elderly African Americans, is too limited and requires additional research to show its rate of use and overall effectiveness.

According to Cuellar, Aycock, Cahill, and Ford (2003), cultural diversity and the health care practices of specific cultures can shape the system of health care in a country. They assert that the assumption that conventional medical practice is the choice for all cultures is incorrect and the inclusion of indigenous healing practices or folk remedies is often ignored or not discussed. In response to the gap in the literature on CAM use by older adults of different racial backgrounds, specifically in rural areas, Cuellar et al. conducted a study undertaken to provide preliminary information for future research on the measurement of outcomes and evidence-based practice in relation to CAM use. The results of the study indicated that, when compared with Whites, African Americans used fewer CAM products (e.g., they used an average of three CAM products versus four for Whites per person), were older and less educated, and were less/more satisfied with CAM use. Although the study identified the CAM modalities used by older rural adults $(N=183)$ to include prayer $(N=155)$, vitamins $(N=151)$, exercise $(N=117)$, meditation $(N=44)$, herbs $(N=43)$, chiropractic medicine $(N=30)$, glucosamine $(N=28)$, and music therapy $(N=21)$, use was not delineated by race. Cuellar et al. concluded that health care providers must be aware of the different uses of CAM by race; suggesting that older African Americans may have specific concerns because of gerontological issues that may increase susceptibility to CAM interventions. They also argued that differences in CAM use by race must be considered when advising patients. Similarly, support for this position is offered by Ness, Cirillo, Weir, Nisly, and Wallace (2005) and Yoon, Horne, and Adams (2004).

In a study on herbal product use by African-American older women, Yoon et al. (2004) reported $33 \%$ of participants used herbal products and perceived their overall health to be better than those who did not use herbal products. Moreover, over $40 \%$ of them did not discuss their use with health care providers and mixed herbal, prescription, and over-the-counter products. Yoon et al. concluded that indiscriminate use of herbal products, in combination with, or in place of, conventional medicines can be problematic and costly. In another study, Ness et al. (2005) studied the use of complementary medicine in older Americans and found African Americans used fewer dietary supplements and fewer chiropractic services, but they reported more personal practices (e.g., breathing exercises, meditation) than Whites.

Some African Americans believe that their illnesses are magical and are outside the realm of nature and unreachable by approaches that might be effective for natural illnesses. Only a powerful healer with supernatural powers can put on or take off a hex, while other folk healers or orthodox physicians will be unable to undertake such acts. In fact, it is further believed that the more often the victim of an unnatural illness visits a doctor, the sicker he or she will become. However, a person who believes in hexes will try a biomedical cure first, both as a way of confirming the existence of a 
hex and as a means of "testing" the physician's diagnostic ability and the "power" of his or her medicine (Diversity Resources, 2000). This finding is supported by earlier studies by Snow $(1974,1978,1983)$.

\section{Current Healing Techniques}

Indigenous healing techniques vary and are specific to regional influence. In addition, educational attainment, personal maturation, and connection to one's cultural identity influence the scope and utilisation of indigenous healing practices. While it is beyond the scope of this article to provide a comprehensive presentation of all practices, it is my intent to provide a sampling of the most commonly known and most frequently used practices. As indicated earlier, African Americans tend to use spirituality, prayer, hope and healing, faith healing, music and healing rhythms, rituals, potions, roots, plants, and herbs to treat certain illnesses and conditions. Other indigenous healing and helping practices that are pervasive among African Americans, especially for emotional or mental health issues, include kinship systems, spiritualism-religion (Gelfand, 2003; Lee, Oh, \& Mountcastle, 1992), "home psychoanalysis" (Hooks, 1993), and conversation and listening (talking with friends/ relatives) (Husaini, Moore, \& Cain, 1991). According to Hooks (1993), informal spaces (i.e., home psychoanalysis) where people feel free to share their stories and receive non-judgmental support are necessary, so that people may heal and move forward, catch their breaths, regain and create new rhythms, and reclaim their voices. Often, among [elderly] African-American women this home psychoanalysis is "kitchen talk," which is an informal gathering of friends around the kitchen table to eat and talk about whatever is on their hearts and minds (Robinson \& HowardHamilton, 2000). In contrast to scientific intervention, home psychoanalysis integrates individuals' communications with their performance in healing rituals.

African-American folk practitioners include grannies, the spiritualist, the voodoo priest or priestess, supernatural healers, and witches (Eaves, 2005). Examples of home remedies include garlic for reducing high cholesterol and high blood pressure, molasses for treating a sore throat, and a penny tied to the ankle to cure rheumatism. Many older African Americans commonly rely on the Almanac to determine the best dates to have certain medical issues addressed. The Almanac is a book that is used by farmers to indicate or predict the best dates for planting and harvesting crops. In addition, the belief in numbers as either lucky or unlucky is used frequently in deciding on the dosage for home remedies and magical rituals (Diversity Resources, 2000).

\section{Cultural Influences}

African Americans develop a particular worldview that emphasises beliefs often derived from their racial and cultural experiences (Brooks, Haskins, \& Kehe, 2004). This worldview includes collectivism (versus individualism), connectedness with community (i.e., family and support networks such as friends, church, and other organisations), interdependence, communal harmony, and harmony with nature 
(Carter, 2002; Middleton, 2005). African Americans share a heritage of ongoing trauma and strong kinship bonds, which remains key in coping with the adversities of society. According to Parham (1996), the African-centred worldview begins with "consubstantiation" (recognition that things within the universe are interconnected), and "the sense of interrelationship between all things which is essential for understanding the relationship between African American people and the context of their lives" (p. 181). Influences on African-American folk beliefs and folk medicine are historical, societal or sociopolitical, economic, educational, familial, and geographic (Eaves, 2005).

African Americans' worldview greatly influences their beliefs toward and use of indigenous healing and helping practices. For example, the skills used in traditional medicine in the "low country" (Charleston, South Carolina) were passed on from mother to daughter. From a young age, girls learned from their mothers which herbs work best for curing particular aliments. Each individual family had its own traditions concerning what herbs or roots they used for particular problems, but whenever an illness arose that they did not know how to handle, families often turned to the eldest woman in the area for advice (Traditional Medicine in the Low Country, 1998). Typically, healers comprise one of three categories: (a) persons who learned their craft from others (e.g., a grandmother, a neighbour, a nursing or medical school); (b) healers on whom God has bestowed the gift of healing during a religious experience; and (c) persons born with the power of curing (God's sign is on such persons at the time of birth) (Eaves, 2005).

African Americans in rural areas possess certain beliefs about medical treatment and a mistrust of the medical community. Historically, African Americans have exhibited mistrust of formal health services due to their experiences with prejudice, discrimination, or culturally insensitive treatment (Brooks et al., 2004). Much of this distrust is related to unethical testing conducted on African Americans during slavery and in research studies in the twentieth century. Examples of the types of research include the following. The first example is the Federal government-sponsored research known as the "Tuskegee experiment" in which 600 African-American men with syphilis were untreated for a more than 40-year period to investigate the impact of the disease on the body (Helms \& Cook, 1999). A second example is the federally sponsored radiation cancer studies in which an unspecified number of AfricanAmerican cancer patients, who thought they were being treated for their disease, were actually injected with radiation in unrelated body sites so that scientists could study the effects of radiation on the body (Reid, 1978). A third example of unethical research conducted on African Americans is the ongoing sterilisation and reproduction research involving African-American women (Bourgois, 2000; Reid, 1978). Thus, "given a history that runs from experimentation on slaves to public health efforts gone awry in sickle cell screening and involuntary sterilization, conspiracy theories cannot be simply written off as paranoia or hypersensitivity" (Corbie-Smith \& Arriola, 2001, p. 492).

In a study of attitudes and beliefs toward participation in medical research, CorbieSmith, Thomas, Williams, and Moody-Ayers (1999) found that African-American 
participants consistently reported a mistrust of doctors, scientists, and the government. In addition, the participants in this study cited the Tuskegee Syphilis Study as a major reason for their mistrust. One may infer, therefore, that many African Americans find cultural comfort and validation with a traditional healer in an indigenous healing system. This, in tandem with a basic belief in the effectiveness of the healer, can make an indigenous model far more appealing than biomedical or scientific intervention (Lee, 1996).

\section{Health Service}

Despite the existence of an advanced, highly institutionalised medical system and the availability of mental health professionals in the United States, it is evident that many types of indigenous healing methods are still utilised by elderly African Americans for physical health or mental health problems. The National Institutes of Health (2004) reported that only $10-30 \%$ of worldwide health care is delivered by conventional biomedically oriented practitioners. In addition, in rural, poor, and marginalised populations (e.g., rural elderly African Americans) the number of indigenous practitioners often exceeds western-trained doctors. However, for fear of ridicule, patients who make use of folk healing methods will probably not admit it to the caregiver (Diversity Resources, 2000). According to Walker and Singleton (1999), the distrust of western medicine is one of the reasons for the bad health statistics for African Americans. In addition, denial of medical issues is one of the biggest problems because African Americans worry that the doctor will confirm their fears.

Integration of indigenous and western healing systems for health care requires a respect for and an understanding of indigenous concepts. Indigenous and biomedical systems of health care can coexist and lend support to one another without compromising and contradicting each other. The intersection of science and nature is not new, nor is it dichotomous (Harley, 2005a). However, there is mixed acceptance among public health practitioners and researchers towards indigenous healing practices. The scientific tradition inherent in western biomedical interventions tends to devalue indigenous healing practices because they do not lend themselves to empirical investigation, and thus provide no scientific basis for therapeutic effectiveness (Lee, 1996). According to Smith (1999), the real issue "may no longer be over the recognition that indigenous people have ways of knowing the world which are unique, but over proving the authenticity of, and control over, our own forms of knowledge" (p. 104). That is, "for the validity of indigenous knowledges" (Lee, 1996, p. 104)

Even with the strides and unparalleled contributions of biomedicine to global health, its programmes often fail to reach those most at risk, and its ever-rising costs and complex and expensive technologies limit its availability. Moreover, biomedicine continues to struggle to communicate the western medical paradigm to indigenous cultures, and consequently, biomedically based health care is often ineffectively delivered to rural elderly African Americans, resulting in suboptimal care at signifi- 
cant expense (Pro-Cultura, Inc., 2004). According to Sherr and Blumhardt (2005), elderly African Americans in rural areas in the United States have difficulties in accessing adequate services, have poor diets, ignore or are unaware of warning symptoms of disease, do not properly monitor their prescription medications, and do not have regular physical checkups. While the health profile of other ethnic minority groups is improving, the prognosis for African Americans is deteriorating (Walker \& Singleton, 1999). Thus, it is necessary for elderly African Americans to find a medical doctor who is informed and sensitive to their unique health needs. This may mean consulting with practitioners of indigenous or natural medicine who can offer a complementary approach to healing (Walker \& Singleton). Likewise, when deciding to integrate indigenous and biomedical healing systems, one must weigh the ethical considerations, especially the ethical principles of beneficence (promoting the individual's well-being), non-maleficence (avoiding or preventing harm to the individual), and autonomy (respecting the individual's freedom to make choices and decisions) (Harley, 2005a).

\section{Interdisciplinary Relevance}

The World Health Organization (2004) indicated that indigenous medicine has a central role to play in the twenty-first century. Thus, collaborative links between communities of indigenous practices and public health offer potential for prevention, intervention, and management of diseases and chronic illnesses. In fact, other disciplines (e.g., social work, cross-cultural psychology, cultural studies, counselling psychology, anthropology, mental health, medical sociology, biology and medicine, rehabilitation counselling) are recognising the value of CAM practices and have devoted increasing attention to their role as part of treatment for clients and patients. In addition, there are now an increasing number of articles, special journal issues (such as this Special Issue), guides, book chapters, and books on traditional medicine, spirituality, indigenous healing, and alternative medicine (e.g., Denzin, 2005; Diversity Resources, 2000; Eisenberg, 1993; Harley, 2005a; Harley et al., 2005; Helms \& Cook, 1999; Jackson, 1992; fournal of Counseling \& Development, 2000, Vol. 78, No. 2; Kim \& Berry, 1993; Lee, 1996; Lee \& Armstrong, 1995; Monitor on Psychology, 2003, Vol. 34; No. 11; Pachter, 1994; Rehabilitation Education, 1995, Vol. 9; No. 2\&3; Rivera et al., 2004; Western fournal of Medicine, 1993, Vol. 157; Wolinsky, 1980). According to Smith (2005), "conversations about indigenous methodologies - albeit in different historical, disciplinary, and institutional spacesare being discussed and applied by a diverse range of indigenous scholars across the globe" (p. 92).

Various disciplines have also shown an increasing awareness that self-treatment, folk medicine, and home remedies are far and away the major source of health care in the United States. Just as various societies that have had substantial cross-cultural contact have always borrowed and assimilated the health beliefs and practices of those with whom they came in contact, so too have various disciplines. Clearly the society of the United States is no different in regard to indigenous healing practices 
(Hufford, 1997). An opportunity to understand indigenous healing practices is lacking in quantitative research, which is of limited practical value in gaining insight into explaining "why" people believe and act as they do. Substantial information can be obtained from community members' experiences, perceptions, and practices.

One major area in which indigenous healing practices warrant additional attention is that of participatory action research. Researchers must not only include elderly African Americans as research participants, but as researchers themselves. Too often, the value of those with first-hand experiences is ignored when studies are designed. The participatory model of research is designed to advance practical knowledge, use interpretive and inductive methods, promote co-control between the researcher and the community, and have the subjects be active rather than passive.

Participatory research is a rational approach to use with this population for several reasons. The first reason is that much of the research produced by the scientific community is not useful to practitioners, to programme strategists, or to service agencies in ethnic communities, because, too often, the goal is evaluation of services and the use of standardised measurement. As such, the traditional scientific mode of scientific research used by academic researchers does not fit the nature of ethnic communities and their goals of social change or service. Another reason for limited utility of traditional methods with this population is that it does not involve participation by the community in the identification of the prevention or intervention. Third, African-American communities are not organised with sets of rules for the accumulation of scientific knowledge. Instead, these communities are organised around primary (i.e., person-to-person) relationships rather than secondary ones (i.e., person-to-system). Finally, the traditional model of research serves to maintain the power of academic researchers to control the knowledge generation process and, consequently, the interventions to be imposed on the African-American community (Langton \& Taylor, 1995). Below are suggestions of how elderly African Americans can facilitate research based on the participatory model.

First, participants should be engaged in continuous discussion as a team to identify the issues and concerns as perceived by them. Engaging in steps of research planning, problem identification, and construction of research questions is one way to develop the research skills of participants, and the legitimising of questions. That is, questions tend to have meaning because the frames of reference are those for which they were intended (Lincoln \& Guba, 2000). In addition, community participation in the development of research fosters a sense of ownership (Harley, Stebnicki, \& Rollins, 2000). Second, participants should assist in data collection in their community. In some ways this level of involvement "promotes a critical consciousness which exhibits itself in political as well as practical action to promote change" (Grundy, 1987, p. 154). Third, participants should be assisted in developing skills and sophistication in shifting between the objective, subjective, and reflexive-dialectical perspectives of participatory research in which they see themselves, their understandings, their practices, and their settings from the perspective of $i n d i$ viduals in and around the setting, and then from the perspective of the social (Kemmis \& McTaggart, 2000). Finally, participants should contribute to analysing 
and interpreting data, which then serves to form recommendations and/or interventions. These steps are directly related to each of the previous suggestions because it connects the tri-part notion of theory, enlightenment, and action. The goal is to help participants better understand fundamental problems by raising their collective consciousness (Berg, 2007).

Too frequently, researchers have no connection with the lived realities of participants. However, participants live with the consequences of the changes they make (Kemmis \& McTaggart, 2000). The key to participatory action research is that it is collaborative and aims to transform both theory and practice.

\section{Summary}

Indigenous healing practices among elderly African Americans originated in Africa. Culture, trust/mistrust of the medical community, and access to healing practices and medical services influence elderly African Americans' use of indigenous healing practices. Collectively, African Americans have a belief system of health and healing, but this is applied individually. Elderly African Americans also vary in their interpretation and utilisation of indigenous practices. They may benefit more from a combination of biomedical and indigenous interventions. For many elderly African Americans, biomedical intervention may not be an option due to financial constraints and inaccessibility due to rural residency. Overall, elderly African Americans in rural areas may continue to utilise indigenous methods to treat physical and psychological impairments. To ignore the influence of indigenous healing practices is to neglect a vital resource in the promotion of health care for African Americans.

\section{References}

Alcock, J. E. (1999). Alternative medicine and the psychology of belief. The Scientific Review of Alternative Medicine, 3, 45-52.

Berg, B. L. (2007). Qualitative research methods for the social sciences (6th ed.). Boston, MA: Allyn and Bacon.

Bourgois, P. (2000). Violating apartheid in the United States: On the streets and in academia. In F. W. Twine \& J. W. Warren (Eds.), Racing research, researching race (pp. 187-214). New York: New York University Press.

Brooks, L. J., Haskins, D. G., \& Kehe, J. V. (2004). Counseling and psychotherapy with African American clients. In T. B. Smith (Ed.), Practicing multiculturalism: Affirming diversity in counseling and psychology (pp. 145-166). Boston, MA: Pearson.

Carter, J. H. (2002). Religion/spirituality in African American culture: An essential aspect of psychiatric care. Fournal of the National Medical Association, 94, 371-375.

Center for Traditional Medicine. (2003). About us. Retrieved January 5, 2006, from http:// www.centerfortraditionalmedicine.org

Church Health Center of Memphis, Inc. (2002). CCHF best practices program: Hope E healing. Retrieved January 11, 2006, from http://www.cchf.org?BestPractices/abstracts/CHCHopeand Healing.doc

Council for Scientific Medicine. (2002). A statement in defense of scientific medicine. The Scientific Review of Alternative Medicine. Retrieved January 18, 2006, from http://www.quackwatch.org 
Corbie-Smith, G., \& Arriola, K. (2001). Research and ethics. In R. Braithwaite \& S. Taylor (Eds.), Health issues in the Black community (2nd ed., pp. 489-502). San Francisco: Jossey-Bass.

Corbie-Smith, G., Thomas, S. B., Williams, M. V., \& Moody-Ayers, S. (1999). Attitudes and beliefs of African Americans toward participation in medical research. Fournal of General Internal Medicine, 14, 537.

Coward, R. T., Netzer, J. K., \& Peek, C. W. (1998). Older rural African Americans. In R. T. Coward \& J. A. Krout (Eds.), Aging in rural settings: Life circumstances and distinctive features (pp. 167-185). New York: Springer.

Cuellar, N., Aycock, T., Cahill, B., \& Ford, J. (2003). Complementary and alternative medicine $(\mathrm{CAM})$ use by African American (AA) and Caucasian American (CA) older adults in a rural setting: A descriptive, comparative study. BMC Complementary and Alternative Medicine, 3(8), 1472-1483. Retrieved January 25, 2006, from http://www.biomedcentral.com/ $1472-6882 / 3 / 8$

Denzin, N. K. (2005). Emancipatory discourses and the ethics and politics of interpretation. In N. K. Denzin \& Y. S. Lincoln (Eds.), The Sage handbook of qualitative research (3rd ed., pp. 933958). Thousand Oaks, CA: Sage.

Diversity Resources. (2000). Culture-sensitive health care: African Americans. Retrieved January 25, 2006, from http://www.diversityresources.com/rc_sample/african.html

Eaves, Y. (2005). African Americans and alternative therapies. Retrieved January 25, 2006, from http:/ /www.unc.edu/course/2005spring/nurs/095/001/culturalcompetence/ppts/AAfolkmed.ppf

Eisenberg, D. M. (1993). Unconventional medicine in the United States. The New England fournal of Medicine, 328, 246-252.

Fett, S. M. (2002). Working cures: Healing, health, and power on southern slave plantations. Chapel Hill, NC: University of North Carolina Press.

Gelfand, D. E. (2003). Aging and ethnicity: Knowledge and services (2nd ed.). New York: Springer Publishing.

Grundy, S. (1987). Curriculum: Product or praxis. London: The Falmer Press.

Harley, D. A. (2005a). African Americans and indigenous counseling. In D. A. Harley \& J. M. Dillard (Eds.), Contemporary mental health issues among African Americans (pp. 293-306). Alexandria, VA: American Counseling Association.

Harley, D. A. (2005b). The Black church: A strength-based approach in mental health. In D. A. Harley \& J. M. Dillard (Eds.), Contemporary mental health issues among African Americans (pp. 191-203). Alexandria, VA: American Counseling Association.

Harley, D. A., Savage, T. A., \& Kaplan, L. E. (2005). Racial and ethnic minorities in rural areas: Use of indigenous influence in the practice of social work. In L. H. Ginsberg (Ed.), Social work in rural communities (4th ed., pp. 367-385). Alexandria, VA: Council on Social Work Education.

Harley, D. A., Stebnicki, M., \& Rollins, C. W. (2000). Applying empowerment evaluation as a tool for self-improvement and community development with culturally diverse populations. Fournal of the Community Development Society, 31(2), 348-364.

Helms, J. E., \& Cook, D. A. (1999). Using race and culture in counseling and psychotherapy: Theory and process. Boston, MA: Allyn and Bacon.

Highlen, P. (1996). MCT theory and implications for organizations/systems. In D. W. Sue, A. E. Ivey, \& P. B. Pedersen (Eds.), A theory of multicultural counseling and therapy (pp. 65-85). Pacific Grove, CA: Brooks/Cole Publishing.

Hooks, B. (1992). Black looks: Race and representation. Boston, MA: South End Press.

Hooks, B. (1993). Sisters of the yam: Black women and self-recovery. Boston, MA: South End Press.

Hufford, D. J. (1997). Cultural diversity, alternative medicine, and folk medicine. New Directions in Folklore, 1. Retrieved January 18, 2006, from http://www.temple.edu/islic/newfolk/ medicine.html 
Husaini, B., Moore, S., \& Cain, V. (1991). Psychiatric symptoms and help-seeking behavior among the elderly: Black-White comparisons. Paper presented at the annual meeting of the Historic Black Colleges and Universities Gerontological Association, Norfolk, VA.

Indigenous Law Institute. (2006). Indigenous Law Institute information. Retrieved January 5, 2006, from http://nativeweb.org

Indigenous Women's Network. (2004). Sovereignty and human rights programs. Retrieved January 5, 2006, from http://www.indigenouswomen.org

Jackson, S. W. (1992). The listening healer in the history of psychological healing. American Fournal of Psychiatry, 149, 1623-1632.

Kemmis, S., \& McTaggart, R. (2000). Participatory action research. In N. K. Denzin \& Y. S. Lincoln (Eds.), Handbook of qualitative research (2nd ed., pp. 567-605). Thousand Oaks, CA: Sage.

Kim, U., \& Berry, J. W. (1993). Indigenous psychologies: Experience and research in cultural context. Newbury Park, CA: Sage.

King, J. E. (2001). Culture-centered knowledge: Black studies, curriculum transformation, and social action. In J. A. Banks, \& C. A. McGee Banks (Eds.), Handbook of research on multicultural education (pp. 265-290). San Francisco: Jossey-Bass.

Langton, P. A., \& Taylor, E. G. (1995). Applying a participatory research model to alcohol prevention research in ethnic communities. In P. A. Langton, L. G. Epstein, \& M. A. Orlandi (Eds.), The challenge of participatory research: Preventing alcohol-related problems in ethnic communities (DHHS Publication No. (SMA)95-3042). Washington, DC: U.S. Department of Health and Human Services.

Lee, C. C. (1996). MCT theory and implications for indigenous healing. In D. W. Sue, A. E. Ivey, \& P. B. Pedersen (Eds.), A theory of multicultural counseling and therapy (pp. 86-98). Pacific Grove, CA: Brooks/Cole.

Lee, C. C., \& Armstrong, K. L. (1995). Indigenous models of mental health intervention: Lessons from traditional healers. In J. Ponterotto, J. M. Casas, L. A. Suzuki, \& C. M. Alexander (Eds.), Handbook of multicultural counseling (pp. 441-456). Beverly Hills, CA: Sage.

Lee, C. C., Oh, M. Y., \& Mountcastle, A. R. (1992). Indigenous models of helping in nonwestern countries: Implications for multicultural counseling. Fournal of Multicultural Counseling and Development, 20, 3-10.

Lincoln, Y. S., \& Guba, E. G. (2000). Paradigmatic controversies, contradictions, and emerging confluences. In N. K. Denzin \& Y. S. Lincoln (Eds.), Handbook of qualitative research (2nd ed., pp. 163-188). Thousand Oaks, CA: Sage.

Middleton, R. A. (2005). Mental health challenges of African American elders: Issues, interventions, and cultural considerations. In D. A. Harley \& J. M. Dillard (Eds.), Contemporary mental health issues among African Americans (pp. 75-90). Alexandria, VA: American Counseling Association.

Morris, E. F. (2000). Assessment practices with African Americans: Combining standard assessment measures within an Africentric orientation In R. H. Dana (Ed.), Handbook of crosscultural and personality assessment (pp. 573-603). Mahawah, NJ: Lawrence Erlbaum Associates.

Mpofu, E., \& Harley, D. A. (2002). Disability and rehabilitation in Zimbabwe: Lessons and implications for rehabilitation practice in the U.S. Fournal of Rehabilitation, 68, 26-33.

Myers, L. (1988). Understanding an Afrocentric worldview: Introduction to an optimal psychology. Dubuque, IA: Kendall/Hunt.

Nahin, R. L., \& Straus, S. E. (2001). Research into complementary and alternative medicine: Problems and potential. British Medical fournal, 322, 161-164.

National Center for Complementary and Alternative Medicine. (2004a). About the National Center for Complementary and Alternative Medicine. Retrieved January 6, 2006, from http:// www.nccam.nih.gov/aboutnccam/index.htm

National Center for Complementary and Alternative Medicine. (2004b). Important events in NCCAM history. Retrieved January 6, 2006, from http://www.nccam.nih.gov/about/ataglance/ timeline.htm 
National Institutes of Health. (2004). Health information 2004. Retrieved January 6, 2006, from http://www.nih.gov

Ness, J., Cirillo, D. J., Weir, D. R., Nisly, N. L., \& Wallace, R. B. (2005). Use of complementary medicine in older Americans: Results from the health and retirement study. The Gerontologist, 45, 516-524.

Nicholls, R. W. (1995). Pragmatic spirituality: Enablement in traditional Africa. Rehabilitation Education, 9, 147-158.

Obomsawin, R. (2002). Indigenous knowledge and sustainable development. Development Express. Retrieved January 9, 2006, from http://www.acdi-cida.gc.ca/cida_ind.nsf

Pachter, L. M. (1994). Culture and clinical care. Fournal of the American Medical Association, 271, $127-131$.

Parham, T. A. (1996). MCT theory and African-American populations. In D. W. Sue, A. E. Ivey, \& P. B. Pedersen (Eds.), A theory of multicultural counseling and therapy (pp. 177-191). Pacific Grove, CA: Brooks/Cole Publishing.

Parham, T. A., \& Parham, W. D. (1997). Therapeutic approaches with African American populations. Newbury Park, CA: Sage.

Parry, B. (1994). Resistance theory/theorising resistance or two cheers for nativism. In F. Barker, P. Hulme, \& M. Inversen (Eds.), Colonial discourselpostcolonial theory (pp. 172-196). Manchester, UK: Manchester University.

Phillips, F. B. (1990). NTU psychotherapy: An Afrocentric perspective. The fournal of Black Psychology, 17, 55-74.

Pinckney, R. (1998). Blue roots: African-American folk magic of the Gullah people. St Paul, MN: Llewellyn Publications.

Pro-Cultura, Inc. (2004). African healing wisdom: From tradition to current application and research. Retrieved January 6, 2006, from http://www.procultura.org/AFRICA.htm

Reid, I. S. (1978). Health issues facing Black women. In M.N. Hill, J. Joe, C. Reyes, \& G. Williams (Eds.), Women's Research Program Educational Equity Group: Vol. 2 research papers (pp. 203-224). Washington, DC: U.S. Department of Health, Education and Welfare.

Rivera, E. T., Garrett, M. T., \& Crutchfield, L. B. (2004). Multicultural interventions in groups: The use of indigenous methods. In J. L. DeLucia-Waack, D. A. Gerrity, C. R. Kalodner, \& M. T. Rivera (Eds.), Handbook of group counseling and psychology (pp. 295-306). Thousand Oaks, CA: Sage.

Robinson, T. L., \& Howard-Hamilton, M. F. (2000). The convergence of race, ethnicity, and gender: Multiple identities in counseling. Upper Saddle River, NJ: Merrill.

Rosmaiti, G. J. (1999). Healing rhythms: An interview with Darrell Rose. Retrieved January 11, 2006, from http://www.hicom.net/ oedipus/darrell.html

Sherr, M. E., \& Blumhardt, F. (2005). Rural elderly women: A triple jeopardy population. In L. H. Ginsberg (Ed.), Social work in rural communities (4th ed., pp. 465-486). Alexandria, VA: Council on Social Work Education.

Smith, L. T. (1999). Decolonizing methodologies: Research and indigenous peoples. Dunedin, New Zealand: University of Otago Press.

Smith, L. T. (2005). On tricky ground: Researching the native in the age of uncertainty. In N. K. Denzin \& Y. S. Lincoln (Eds.), The Sage handbook of qualitative research (3rd ed., pp. 85-107). Thousand Oaks: CA, Sage.

Snow, L. F. (1974). Folk medical beliefs and their implications for care of patients: A review based on studies among Black Americans. Annals of Internal Medicine, 81, 82-96.

Snow, L. F. (1978). Sorcerers, saints and charlatans: Black folk healers in urban America. Culture, Medicine and Psychiatry, 2, 69-106.

Snow, L. F. (1983). Traditional health beliefs and practices among lower class Black Americans. Western fournal of Medicine, 139, 820-828.

Traditional Medicine in the Low Country. (1998). Retrieved January 18, 2006, from http:// northbysouth.kenyon.edu/1998/health/tradistsc.htm 
Trieschmann, R. B. (1995). The energy model: A new approach to rehabilitation. Rehabilitation Education, 9, 217-227.

Walker, M. A., \& Singleton, K. B. (1999). Natural health for African Americans. New York: Lynn Sonberg.

Weenie, A. (2000). Post-colonial recovering and healing. In J. Reyhner, L. Lockard, \& W. S. Gilbert (Eds.), Learn in beauty: Indigenous education for a new century (pp. 65-70). Flagstaff, AZ: Northern Arizona University.

Wolinsky, T. (Ed.). (1980). Alternative healers and popular medicine. The sociology of health (pp. 291-302). Boston: Little, Brown \& Co.

WorldHealthMD. (2000). Polarity therapy. Retrieved January 11, 2006, from http:// www.wholehealth.com

World Health Organization. (2004). World health report 2004. Retrieved January 11, 2006, from http://www.who/hrh/about_whr04/en

Yoon, S. L., Horne, C. H., \& Adams, C. (2004). Herbal product use by African American older women. Clinical Nursing Research, 13, 271-288.

\section{Appendix. Important events in the U.S. NCCAM's history}

The information summarised in this Appendix was obtained from NCCAM (2004b).

\section{October 1991}

- The U.S. Congress passes legislation (P.L.102-170) that provides $\$ 2$ million in funding for the fiscal year 1992 to establish an office within NIH to investigate and evaluate promising unconventional medical practices.

- Acting Director of the new office, Office of Alternative Medicine (OAM), is appointed.

\section{September 1992}

- A workshop on Alternative Medicine is convened to discuss the state-of-the art of the major areas of alternative medicine and to direct attention to priority areas for future research activities.

\section{October 1992}

- First Director of the OAM is appointed. 


\section{June 1993}

- The National Institutes of Health Revitalization Act of 1993 (P.L.103-43) formally establishes the OAM within NIH to facilitate study and evaluation of CAM practices and to disseminate the resulting information to the public.

\section{September 1993}

- The first OAM research project grants are funded through the National Center for Research Resources.

\section{December 1993}

- The Alternative Medicine Program Advisory Council is established.

\section{October 1995}

- A Research Centers Program is established to provide a nationwide focus for interdisciplinary CAM research in academic institutions.

\section{October 1996}

- A Public Information Clearinghouse is established.

\section{November 1996}

- The OAN is designated as a World Health Organization Collaborating Center in Traditional Medicine.

\section{September 1997}

- The first Phase III clinical trial is funded.

\section{October 1998}

- NCCAM is established by congressional mandate under provisions of the Omnibus Appropriations Bill (P.L.105-277). This bill amends Title IV of the Public Health Service Act and elevates the status of the OAM to an NIH Center.

\section{February 1999}

- A charter creating NCCAM and making it the 25th independent component of the NIH is signed. 


\section{May 1999}

- NCCAM independently awards its first research grant.

- The NCCAM Trans-Agency CAM Coordinating Committee (TCAMCC) is established by the NCCA Director to foster the Center's collaboration across the DHHS and other Federal agencies. This committee supersedes a trans-agency committee established by the NIH Director in 1997.

\section{June 1999}

- A Special Emphasis Panel is chartered to enable NCCAM to conduct peer review of mission-specific CAM applications.

\section{August 1999}

- The National Advisory Council on Complementary and Alternative Medicine (NACCM) is chartered.

\section{September 1999}

- NCCAM awards two multi-center research studies, on ginko biloba for dementia and on glucosamine/chondrotin sulfate for knee osteoarthritis.

\section{June 2000}

- NCCAM collaborates with the National Heart, Lung, and Blood Institute to sponsor a workshop on complementary and alternative medicine in cardiovascular, lung, and blood research.

\section{September 2000}

- NCCAM's first strategic plan is published, entitled Expanding Horizon of Healthcare: Five-Year Strategic Plan 2001-2005.

- Workshop is organised on "The Science of the Placebo: Toward an Interdisciplinary Research Agenda."

\section{February 2001}

- CAM on PubMed, a comprehensive Internet source of research-based information on CAM, is launched by NCCAM and the National Library of Medicine.

\section{April 2001}

- The Division of Intramural Research is established. 
May 2001

- The first draft "Strategic Plan to Address Racial and Ethnic Health Disparities" is published.

\section{June 2001}

- The Office of Scientific Review is established. 